
\title{
25 Research Square \\ Fluid-Screen as a Real Time Dielectrophoretic Method for Universal Microbial Capture
}

Monika Weber ( $\nabla$ monika@fluidscreen.com )

Fluid-Screen, Inc. https://orcid.org/0000-0002-9970-079X

\section{Robert Weber}

Fluid-Screen, Inc.

Janusz Petkowski

MIT https://orcid.org/0000-0002-1921-4848

\section{Brandye Michaels}

Pfizer, Inc

Kamil Wisniewski

Hener

Anna Piela

Fluid-Screen, Inc.

Slawomir Antoszczyk

Fluid-Screen, Inc.

\section{Article}

Keywords:

Posted Date: February 5th, 2021

DOl: https://doi.org/10.21203/rs.3.rs-209056/v1

License: (c) (1) This work is licensed under a Creative Commons Attribution 4.0 International License.

Read Full License

Version of Record: A version of this preprint was published at Scientific Reports on November 15th, 2021. See the published version at https://doi.org/10.1038/s41598-021-01600-z. 


\section{Abstract}

Dielectrophoresis (DEP) has shown great promise for particle separation for decades; however, it has not yet been widely applied in routine laboratory setting. This paper provides an overview of a new DEP microbial capture and separation method called Fluid-Screen (FS), that achieves an efficient, reliable and repeatable capture and separation of microbial cells. Method verification experiments demonstrated that the FS system captured $100 \%$ of bacteria in test samples, a capture efficiency much higher than previously reported for similar technology. Data generated supports the superiority of the FS method as compared to the established Plate Counting Method (PCM), that is routinely used to detect bacterial contamination in healthcare, pharmacological and food industries. We have established that the FS method is universal and can capture and separate different species of bacteria and fungi to viruses, from various sample matrices (i.e. human red blood cells, mammalian cells).

\section{Introduction}

Microbial (i.e. bacterial, viral and fungal) contamination is a serious and global threat to human health and economic development. The gold-standard method to assess the degree of microbial contamination is Plate Counting Method (PCM) ${ }^{1}$. Culture methods are still a standard, routine, techniques used in medical, pharmacological and food industries to identify bacterial contamination ${ }^{2}$. Unfortunately, the time-to-results for PCM is slow (days), requires the growth of the microorganisms under specific conditions used in the procedure and may lead to the underestimation of the microorganisms population, labor intensive, and prone to human error such as media preparation, serial dilutions during sample preparation, or changing procedure condition. Moreover, the PCM method can only count and detect metabolically active cells that are capable of cell division. There is a need for new technologies that allow for faster microbial detection and assessment of microbial contamination.

Dielectrophoresis (DEP) has shown great promise for particle separation for decades (see excellent reviews $^{3-5}$ ). Several DEP systems show promising potential applications in medical sciences, including drug delivery or cancer diagnostics ${ }^{6-11}$. However, DEP has not yet been widely applied in clinical settings. Only small sample volumes with high bacterial concentrations on the order of $10^{3}-10^{7} \mathrm{cfu} / \mathrm{mL}$ have been processed, which is a limitation of the applicability of DEP microbial capture methods ${ }^{12-14}$. DEP particle separation has been achieved only to a limited extent and the separation is restricted to specific cell types, (see e.g. ${ }^{4}$ ), and is mostly applicable to metabolically active cells ${ }^{15}$. Unfortunately, separation of small cells and viral particles $(\sim 1 \mu \mathrm{m}$, and sub- $\mu \mathrm{m}$ in diameter - the size of many pathogenic bacteria and viruses) with DEP method is notoriously difficult. In brief, small bacterial particles will undergo significant Brownian motion that will add time dependent variation in their position and thus the specificity of separation will decrease for small cells limiting the applicability of the method (see e.g. ${ }^{16}$ ).

In this paper we show the new DEP bacterial capture and separation method, that overcomes those notorious limitations. We call our DEP microbial capture method Fluid-Screen (FS). We confirm high 
reproducibility of the method by measuring the efficiency of the bacterial capture with the Fluid-Screen system and show the superiority of the FS method as compared to the established method, namely Plate Counting Method (PCM) (Section 2.1.1). We establish that the FS method is universal and captures very diverse particles, from different cells to viruses (Section 2.1.2) and can separate bacteria form physiologically relevant fluids (i.e. human red blood cells) (Section 2.1.3). We summarize and discuss our results and the applications of the Fluid-Screen system in Section 3.

\section{Results}

In this section we describe the DEP microbial capture and separation method called Fluid-Screen (FS). First, we provide a brief overview of the design of the FS system followed a detailed verification of the FS method (Section 2.1).

The overall schematic of the operation of the Fluid-Screen System (FS) is shown on Figure 1. In brief, concentration of bacteria in a sample (influent sample contained microbes) is determined by measuring optical density (OD) and by culture and enumerated using PCM to confirm concentration in $\mathrm{cfu} / \mathrm{mL}$. The FS system pumps the influent sample through the microfluidic chip with a system of electrodes. The electrodes in the chip generate an electric field. As bacteria enter the chip, electric field captures bacteria on the electrodes. The effluent sample is collected in a tube at the outlet of the chip.

After the Fluid-Screen System processes the entire influent sample and quantifies the number of captured bacteria, effluent sample is collected, cultured, and enumerated using PCM for the confirmation of FS performance.

For details on the engineering design (Section S1.1), microfabrication (Section S1.2) as well as microbial sample preparation (Section S1.3, Section S1.4, Section S1.5) and FS bacterial capture procedure (Section S1.6) see Online Methods.

\subsection{Verification of the Fluid-Screen Method}

In this section we empirically verify the repeatability of the Fluid-Screen dielectrophoretic capture method (FS). First, we experimentally determine the efficiency of bacterial capture and demonstrate the superiority of the Fluid Screen capture method over the clinically established standard Plate Count Method (PCM) (Section 2.1.1). Secondly, we show that the FS method is equally applicable in capturing very diverse microorganisms, not only bacteria (Section 2.1.2). Lastly, we verify the FS capture method, in a physiologically relevant setting by selective capture of bacterial cells from human red blood cells (Section 2.1.3).

\subsubsection{The Efficiency of Bacterial Capture with Fluid Screen System}

We demonstrate that the FS system with the Fluid-Screen chip captures $100 \%$ of bacteria. Following general guidelines accepted number of colonies for reliable quantification of contamination is between 
30 and $250^{17}$. For verification of new methods, the US Pharmacopeia (USP) requires that results are within $+/-0.5 \mathrm{log}$. For this reason, the metrics of $+/-0.5$ log range is the basis for results evaluation with FS method. This paper presents the results on verification of this new method.

Our achieved $100 \%$ capture efficiency is much higher than previously reported capture efficiency results, for the similar technology ${ }^{18}$. We verify the $100 \%$ capture efficiency for E. coli-8739 by two different counting methods.

First, we confirm the capture efficiency of the unstained bacteria with the standard Plate Counting Method (PCM), we call it "PCM quantification" (Figure 2a). The capture efficiency is defined accordingly to the following formula:

$$
\text { Capture efficiency }=\left(1-\frac{\text { conc }_{\text {eff }}}{\text { conc }_{\text {inf }}}\right) \cdot 100 \%
$$

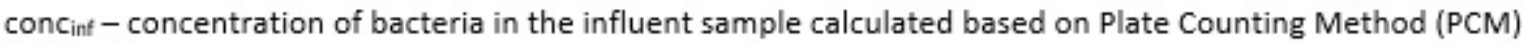
$[\mathrm{cfu} / \mathrm{mL}]$

conceff - concentration of bacteria in the effluent sample calculated based on Plate Counting Method (PCM) $[\mathrm{cfu} / \mathrm{mL}]$

Second, we visualize captured bacteria in the sample by fluorescence microscopy with SYBR-Green staining and determine their exact number of by a direct "on chip quantification" (Figure 2b). This process demonstrates the real number of bacteria present in the sample.

Figure 2 shows the general schematic of the FS experimental setup for both verification approaches ("PCM quantification" and "on chip quantification"). For the experiment, the influent containing E. coli bacteria was processed on the FS setup. In each experiment $1 \mathrm{~mL}$ of the effluent (output sample) was collected and plated immediately on MAC agar plates for enumeration using PCM to calculate the number of Colony Forming Units (cfus). The Electric Field settings allowing for efficient bacteria capture were determined based on a standard in-house calibration protocol (see SI, Sections S1.3 and S1.4).

FS demonstrates an overall $100 \%$ bacterial capture efficiency, as verified by "PCM quantification" approach. The unstained $E$. coli capture experiment was repeated in 3 biological replicates (a biological replicate is new separately grown bacterial sample) with 3 technical replicates (a technical replicate is a triplicate repetition of the FS capture experiment, done sequentially, from the same biological replicate) per each biological replicate for a total of 9 tests (Figure 3 and Figure S9). All 3 biological repeats on FS system, in each of the 9 total conducted experiments, demonstrate $100 \%$ bacteria capture efficiency and repeatability (Figure 3 and Figure S9). Detailed data of the "PCM quantification" experiments is summarized in Table S1, including the number of bacterial colonies in the negative control, bacterial concentration in influent, bacterial concentration in effluent and the calculated capture efficiency. The number of cfus in each influent was between $20 \mathrm{cfu} / \mathrm{mL}$ and $420 \mathrm{cfu} / \mathrm{mL}$. 
Note that in the "PCM quantification" experiment bacteria in influent were not stained with any fluorescent stain. Lack of bacterial staining in a "PCM quantification" experiment avoids any potential growth inhibition by the fluorescent dye on MAC agar plates. For all conducted experiments, acceptable growth, and variability range +/- $0.5 \mathrm{log}$ was reported as recommended by the USP for new method verification. The details on bacterial sample preparation are described in Online Methods, Section S1.3.1.

The direct "on chip quantification" of SYBR-Green stained E. coli is a second approach to experimentally demonstrate the FS $100 \%$ bacteria capture efficiency (Figure 3). The direct "on chip quantification" approach is also designed to experimentally demonstrate the superiority of the FS method over "PCM quantification". The direct FS-counted number of bacteria was determined by background subtraction from total count on the chip (Table 1).

As shown on Figure 3 Fluid-Screen direct "on chip quantification" of captured bacteria is more reliable than a standard established, indirect "PCM quantification", that requires converting the real number of captured bacteria to $\mathrm{cfu} / \mathrm{mL}$ values. Most importantly Fluid-Screen direct "on chip quantification" yields a very small bacteria counting error. The small error is a result of a manual operation of the FS system and can be further decreased in future fully automated versions. "PCM quantification" is generally much less reliable, as it is not only indirect, but it introduces multiple human errors (e.g. during sample preparation and dilution, plating on agar plates, etc.). Therefore, standard "PCM quantification" is subjected to a large statistical error that goes beyond the $+/-0.5$ log the range accepted by USP.

\subsubsection{The Repeatability of Bacterial Capture with Fluid Screen System}

We have also assessed the repeatability of the FS capture experiments. The repeatability verification result shows that the FS system demonstrates very high repeatability in the capture and quantification of bacteria. Moreover, the method is more accurate than the required $+/-0.5 \log$ accepted by the USP for new method verification (see Figure 3 and SI Section S2.2; Figure S10, Figure S11, Table S2). 


\begin{tabular}{|c|c|c|c|c|c|c|c|c|c|}
\hline \multicolumn{10}{|c|}{ Plate-Count Method [cfu/mL] “PCM quantification” } \\
\hline & \multicolumn{3}{|c|}{ Biol Rep 1} & \multicolumn{3}{|c|}{ Biol Rep 2} & \multicolumn{3}{|c|}{ Biol Rep 3} \\
\hline & $\begin{array}{c}\text { Tech } \\
\text { Rep } 1 \\
\text { [Ave } \\
\text { cfu/mL] }\end{array}$ & $\begin{array}{c}\text { Tech } \\
\text { Rep 2 } \\
\text { [Ave } \\
\text { cfu/mL] }\end{array}$ & $\begin{array}{c}\text { Tech } \\
\text { Rep } 3 \\
\text { [Ave } \\
\text { cfu/mL] }\end{array}$ & $\begin{array}{c}\text { Tech } \\
\text { Rep 1 } \\
\text { [Ave } \\
\text { cfu/mL] }\end{array}$ & $\begin{array}{c}\text { Tech } \\
\text { Rep } 2 \\
\text { [Ave } \\
\text { cfu/mL] }\end{array}$ & $\begin{array}{c}\text { Tech } \\
\text { Rep } 3 \\
\text { [Ave } \\
\mathrm{cfu} / \mathrm{mL}]\end{array}$ & $\begin{array}{c}\text { Tech } \\
\text { Rep 1 } \\
\text { [Ave } \\
\text { cfu/mL] }\end{array}$ & $\begin{array}{c}\text { Tech } \\
\text { Rep } 2 \\
\text { [Ave } \\
\text { cfu/mL] }\end{array}$ & $\begin{array}{c}\text { Tech } \\
\text { Rep } 3 \\
\text { [Ave } \\
\text { cfu/mL] }\end{array}$ \\
\hline $\begin{array}{l}\text { Neg } \\
\text { (FTR } \\
\text { control } \\
\text { buffer) }\end{array}$ & 0 & 0 & 0 & 0 & 0 & 0 & 0 & 0 & 0 \\
\hline $\begin{array}{l}\text { Influent } \\
\leq 250 \\
\text { cfu/mL }\end{array}$ & 70 & 20 & 17 & 52 & 12 & 42 & 65 & 53 & 20 \\
\hline Effluent & 0 & 0 & 0 & 0 & 0 & 0 & 0 & 0 & 0 \\
\hline $\begin{array}{l}\text { Cap }_{\text {eff }} \\
{[\%]}\end{array}$ & 100 & 100 & 100 & 100 & 100 & 100 & 100 & 100 & 100 \\
\hline \multicolumn{10}{|c|}{ Direct FS baseline of particles “On-Chip Quantification” [particles/mL] } \\
\hline $\begin{array}{l}\text { FS } \\
\text { baseline } \\
\text { of } \\
\text { particles }\end{array}$ & 6 & 15 & 3 & 4 & 3 & 12 & 26 & 13 & 5 \\
\hline \multicolumn{10}{|c|}{ Direct total particle capture “On-Chip Quantification" [particles/mL] } \\
\hline $\begin{array}{l}\text { Total } \\
\text { particle } \\
\text { capture }\end{array}$ & 184 & 130 & 198 & 124 & 179 & 189 & 124 & 128 & 139 \\
\hline \multicolumn{10}{|c|}{$\begin{array}{l}\text { Direct “On-Chip Quantification” (Total particle capture On-Chip minus FS baseline of particles On- } \\
\text { Chip) [bacteria/mL] }\end{array}$} \\
\hline $\begin{array}{l}\text { Total } \\
\text { Capture }\end{array}$ & 178 & 115 & 195 & 120 & 176 & 177 & 98 & 115 & 134 \\
\hline
\end{tabular}

Table 1. Summarized results of PCM and the direct "on chip quantification" demonstrating the FS $100 \%$ bacteria capture efficiency; Abbreviations used in table: Cap $_{\text {eff }}$ - Capture efficiency.

In conclusion, the FS system has demonstrated critical functionality in capturing all bacteria that are present in the test samples, under variable bacterial concentration ranges. The $100 \%$ bacterial capture efficiency was verified both by a standard PCM method and by a high-performance direct on-chip quantification. As presented for $E$. coli the FS system demonstrates very high repeatability of bacterial capture. In addition, it allows to quantify the directly FS-counted number of microorganisms in analyzed samples.

\subsubsection{Fluid Screen System Captures Diverse Microorganisms}

Fluid-Screen technology can capture and detect very diverse microorganisms. It is not limited to E. coli. It captures both Gram (-) and Gram (+) bacteria, multiple bacterial morphologies, and both individual bacteria and cell aggregates, including bacteria cannot be cultured or do not culture easily (e.g. certain 
strains of Mycoplasma hyorhinis and Legionella pneumophila). Herein we demonstrate that not only Gram (-) or (+), bacilli or cocci bacteria, but also yeast and molds (including conidia, conidiophores and hyphae) and viruses (data not shown) respond to the electric field, and therefore can be efficiently captured and separated. A total of 40 different species of microorganisms were tested providing the proof of concept for the broad applicability of FS system. All of microorganisms responded to the electric field and were captured, as verified by optical microscopy (Table 2, Table S3). The detailed statistical analysis of the capture efficiency of the other microbial species is going to be presented in future dedicated follow up studies. 


\begin{tabular}{|c|c|c|c|c|}
\hline \multicolumn{5}{|c|}{ Capturing of microorganisms from a variety of taxa } \\
\hline & $\begin{array}{c}\text { Taxonomy } \\
\text { Domain of Life }\end{array}$ & $\begin{array}{l}\text { Microorganism } \\
\text { Differentiation }\end{array}$ & Media & $\begin{array}{l}\text { Respond to } \\
\text { electric } \\
\text { field }\end{array}$ \\
\hline E. coli-8739 & Bacteria & Gram (-) & $\begin{array}{l}\text { PBS } \\
\text { Drug substance } \\
\text { (concentrated } \\
\text { protein solution) } \\
\text { Mammalian cell } \\
\text { culture medium }\end{array}$ & YES \\
\hline $\begin{array}{l}\text { P. aeruginosa- } \\
9027\end{array}$ & Bacteria & Gram (-) & $\begin{array}{l}\text { PBS } \\
\text { Drug substance } \\
\text { (concentrated } \\
\text { protein solution) } \\
\text { Mammalian cell } \\
\text { culture medium }\end{array}$ & YES \\
\hline $\begin{array}{l}\text { B. cereus } \\
13061\end{array}$ & Bacteria & Gram (+) & PBS & YES \\
\hline $\begin{array}{l}\text { B. coagulans } \\
\text { BAA-738 }\end{array}$ & Bacteria & Gram $(+)$ & PBS & YES \\
\hline $\begin{array}{l}\text { B. circulans } \\
9500\end{array}$ & Bacteria & Gram $(+)$ & PBS & YES \\
\hline $\begin{array}{l}\text { B. megaterium } \\
14581\end{array}$ & Bacteria & Gram (+) & PBS & YES \\
\hline $\begin{array}{l}\text { B. oleronius } \\
700005\end{array}$ & Bacteria & Gram (+) & PBS & YES \\
\hline $\begin{array}{l}\text { B. subtilis } 6051 \\
\text { (including } \\
\text { endospores) }\end{array}$ & Bacteria & Gram (+) & PBS & YES \\
\hline $\begin{array}{l}\text { A. brasiliensis- } \\
16404\end{array}$ & $\begin{array}{c}\text { Eukaryota } \\
\text { Multicellular } \\
\text { (Fungus) }\end{array}$ & Mold & $\begin{array}{l}\text { PBS } \\
\text { Drug substance } \\
\text { (concentrated } \\
\text { protein solution) } \\
\text { Mammalian cell } \\
\text { culture medium }\end{array}$ & YES \\
\hline $\begin{array}{l}\text { C. albicans- } \\
10231\end{array}$ & $\begin{array}{l}\text { Eukaryota } \\
\text { single-celled } \\
\text { (Fungus) }\end{array}$ & Yeast & $\begin{array}{l}\text { PBS } \\
\text { Drug substance } \\
\text { (concentrated } \\
\text { nrntein cnlı ıtinn) } \\
\text { Mammalian cell } \\
\text { culture medium }\end{array}$ & YES \\
\hline $\begin{array}{l}\text { Human } \\
\text { adenovirus } 5 \\
\text { VR-5 }\end{array}$ & N/A & N/A & $\begin{array}{l}\text { PBS } \\
\text { Mammalian cells } \\
\text { cultured medium }\end{array}$ & YES \\
\hline
\end{tabular}

\subsubsection{Separation of Bacterial Cells from Red Blood Cells}

Fluid-Screen system is capable of not only universal capture of diverse microbial organisms, it can also separate them and selectively capture only microbial species of interest. In this section we illustrate the selective capture capability of FS system in physiologically relevant setting, by capturing $E$. coli bacteria from human red blood cells.. 
Separation of bacteria from blood is challenging because blood is a complex fluid. Every microliter of blood contains about 5 million red blood cells, in addition to platelets, white blood cells, and proteins. Blood plasma is a high ionic solution containing proteins and ions, which can add to electric screening or chemical non-specific binding, which in turn could lower the efficiency of FS DEP capture. Overcoming such challenges and achieving reliable and efficient detection of bacteria is crucial in clinical diagnostics. For example, to diagnose sepsis, it is required to detect a single bacterium from $1 \mathrm{~mL}$ of blood. Efficient and accurate separation and capture of bacteria in blood can result in automated and fast sample preparation on chip.

We have separated E. coli bacteria from human red blood cells. The capture and separation of $E$. coli from red blood cells was performed using PDMS FS chips (see Online Methods). The results of the E. coli capture from diluted serum in the presence of red blood cells (RBCs), together with the dielectrophoretic conditions of the bacterial capture are summarized on Figure 4. Our results show a E. coli capture and separation from human red blood cells sample. The detailed statistical analysis of the capture efficiency and separation of bacterial cells from physiologically relevant fluids is a domain of future dedicated work.

In conclusion, we have verified the approach and shown that the Fluid-Screen dielectrophoretic method for universal microbial capture is characterized by high efficiency of capture, with no false negatives and false positives. We show that the method is reliable, shows high repeatability, shows fast response and operation. We showed that FS can work on diluted physiological solutions (i.e. human blood) and shows high yield of separation in the presence of blood cells, thus meets the high selectivity requirements. Most importantly, from the clinical perspective, it can process high volumes of liquid to meet clinical testing standards.

\section{Discussion}

We have presented Fluid-Screen (FS) - a new dielectrophoretic method for universal microbial capture. We have extensively verified Fluid-Screen performance in terms of efficiency and repeatability of $E$. coli capture. The FS method shows fast response and operation (sample processing through FS system takes approx. 4 minutes), and is highly reliable.

The FS method captures $100 \%$ of the bacteria present in all tested samples (Table 1 ; Table S1), as verified both by the established PCM method and by direct bacteria on-chip-quantification (Figure 2 and Figure 3 ). Fluid-Screen demonstrates a highly repeatability of bacterial capture process that provides high levels of confidence (Figure S10), as exemplified by the fact that the Fluid-Screen method meets the error range of $+/-0.5$ log recommended by the USP for new method validation.

Here we demonstrate the superiority of the Fluid-Screen microbial capture over the standard culture method (i.e. PCM). The PCM is a multistep, indirect method of assessing the degree of bacterial contamination. The Fluid-Screen method gives a direct number of cells in the sample without the need for a plating step. Moreover, the established PCM method is only capable of detecting and counting live 
bacteria that form colonies on the plate. FS on the other hand captures and detects all cells, including: alive colony forming ones, alive but metabolically inactive, spores etc., all of which nevertheless can cause serious health hazard if left undetected. The ability of reliably capturing and detecting cells in all of their various metabolic states is a serious improvement over the currently used PCM method (Figure 3).

We have demonstrated that the FS method is capable of capturing plethora of microorganisms from variety of taxa (Table 2 and Table S3), confirming that the FS method is an universal microbial capture approach suitable for capture and identification of any microorganism, from bacteria, to single- and multi-cellular eukaryotes, to viruses (Table 2 and Table S3). We note that some of the captured microorganisms are difficult to identify and count by other methods. FS technology does not require microorganisms to be able to grow in the laboratory conditions, and as such FS can capture and identify microorganisms for which the classical PCM technique would never work.

We have also demonstrated that FS can capture and separate $E$. coli bacteria from human red blood cells (Figure 4).

The versatility of the Fluid-Screen microbial capture method makes it potentially applicable in a variety of clinically relevant settings, including in healthcare, food and pharmacology industry as well as in environmental studies, anywhere where fast and reliable detection of a broad range of microbial contaminants is a paramount.

Taken together, FS technology is not only devoid of the shortcomings of the PCM method, but it is also faster and much more reliable (due to reduction of human intervention and human errors) in the estimation of the bacterial contamination. FS is able to demonstrate a clear advantage over plate count enumeration methods, with higher levels of accuracy indicated by a true, direct bacterial count from the tested samples, and a reduced variability between samples.

The FS method is semi-automatic. It does not require intensive labour (in contrary to PCM), training and has much higher reproducibility.

The engineering design of the Fluid-Screen System is very versatile, allowing for ease of modification and future improvements, including but not limited to automation of the entire process (to further reduce operational errors), miniaturization for environmental studies, online, at line testing etc..

\section{Declarations}

\section{Acknowledgments:}

We want to thank Shari Yosinski, Sonya Sawtelle and Yale University for supporting our efforts, Coli Genetric Stock Center at Yale for bacterial samples. We want to thank Michelle Logsdon, Regina Sor, Michael O'Connor and Fluid-Screen team for their contributions.

\section{Funding:}


This research was supported, in part, by Fluid-Screen, Pfizer.

\section{Author contributions:}

REW - performed experiments, engineering design, experimental design, execution and analysed the data; JJP - analysed the data and wrote the paper; BM - study design, MOC - performed experiments; $\mathrm{KW}$ - engineering design and execution; SA - analysed the data, directed studies, experimental design and wrote the paper; MUW - conceived the technology, performed experiments, directed studies and experimental design, engineering design and execution, analysed the data and wrote the paper.

\section{Competing Interests:}

The authors have been employed by Fluid-Screen or Hener, and have future cash and/or stock payments coming from their continued employment with Fluid-Screen.

\section{References}

1. Jennison, M. W. \& Wadsworth, G. P. Evaluation of the errors involved in estimating bacterial numbers by the plating method. J. Bacteriol. 39, 389 (1940).

2. Abraham, A. et al. Bad Bug Book: Foodborne pathogenic microorganisms and natural toxins handbook. (U. S. Food and Drug Administration, 2014).

3. Zhang, H., Chang, H. \& Neuzil, P. DEP-on-a-chip: Dielectrophoresis applied to microfluidic platforms. Micromachines 10, 423 (2019).

4. Abd Rahman, N., Ibrahim, F. \& Yafouz, B. Dielectrophoresis for biomedical sciences applications: A review. Sensors 17, 449 (2017).

5. Sarno, B., Heineck, D., Heller, M. J. \& Ibsen, S. Dielectrophoresis: Developments and applications from 2010 to 2020. Electrophoresis (2020).

6. Arya, R., Komal, H., Sankaranarayanan, A. \& Krishnamurthy, R. Applications of Dielectrophoresis in the Field of Medical Sciences. Int. J. Sci. Res. 4, 328-341 (2018).

7. Hoque, R., Mostafid, H. \& Hughes, M. P. Rapid, low-cost dielectrophoretic diagnosis of bladder cancer in a clinical setting. IEEE J. Transl. Eng. Heal. Med. 8, 1-5 (2020).

8. Coll De Peña, A. et al. Analysis of bacteriophages with insulator-based dielectrophoresis. Micromachines 10, 450 (2019).

9. Guan, Y. et al. Dielectrophoresis Separation of Platelets Using a Novel Zigzag Microchannel. Micromachines 11, 890 (2020).

10. Jaffe, A. \& Voldman, J. Multi-frequency dielectrophoretic characterization of single cells. Microsystems Nanoeng. 4, 1-9 (2018).

11. Lewis, J. et al. A pilot proof-of-principle Analysis Demonstrating Dielectrophoresis (Dep) as a Glioblastoma Biomarker platform. Sci. Rep. 9, 1-10 (2019). 
12. Alizadeh, M. et al. Rapid separation of bacteria from blood-Chemical aspects. Colloids Surfaces $B$ Biointerfaces 154, 365-372 (2017).

13. Pitt, W. G. et al. Rapid separation of bacteria from blood-review and outlook. Biotechnol. Prog. 32, 823-839 (2016).

14. Cheng, I.-F., Chen, T.-Y., Lu, R.-J. \& Wu, H.-W. Rapid identification of bacteria utilizing amplified dielectrophoretic force-assisted nanoparticle-induced surface-enhanced Raman spectroscopy. Nanoscale Res. Lett. 9, 324 (2014).

15. Voldman, J. Electrical forces for microscale cell manipulation. Annu. Rev. Biomed. Eng. 8, 425-454 (2006).

16. Kuczenski, R. S., Chang, H.-C. \& Revzin, A. Dielectrophoretic microfluidic device for the continuous sorting of Escherichia coli from blood cells. Biomicrofluidics 5, 32005 (2011).

17. Pharmacopeia, U. S. 61-Microbiological examination of nonsterile products: Microbial enumeration tests. USP 31/FN26. in Usp Pharmacists' Pharmacopeia; United States Pharmacopeial Convention: Rockville, MD, USA S3 (2009).

18. Choi, J.-W. et al. 3-dimensional electrode patterning within a microfluidic channel using metal ion implantation. Lab Chip 10, 783-788 (2010).

19. Castellarnau, M., Errachid, A., Madrid, C., Juarez, A. \& Samitier, J. Dielectrophoresis as a tool to characterize and differentiate isogenic mutants of Escherichia coli. Biophys. J. 91, 3937-3945 (2006).

\section{Figures}


a)

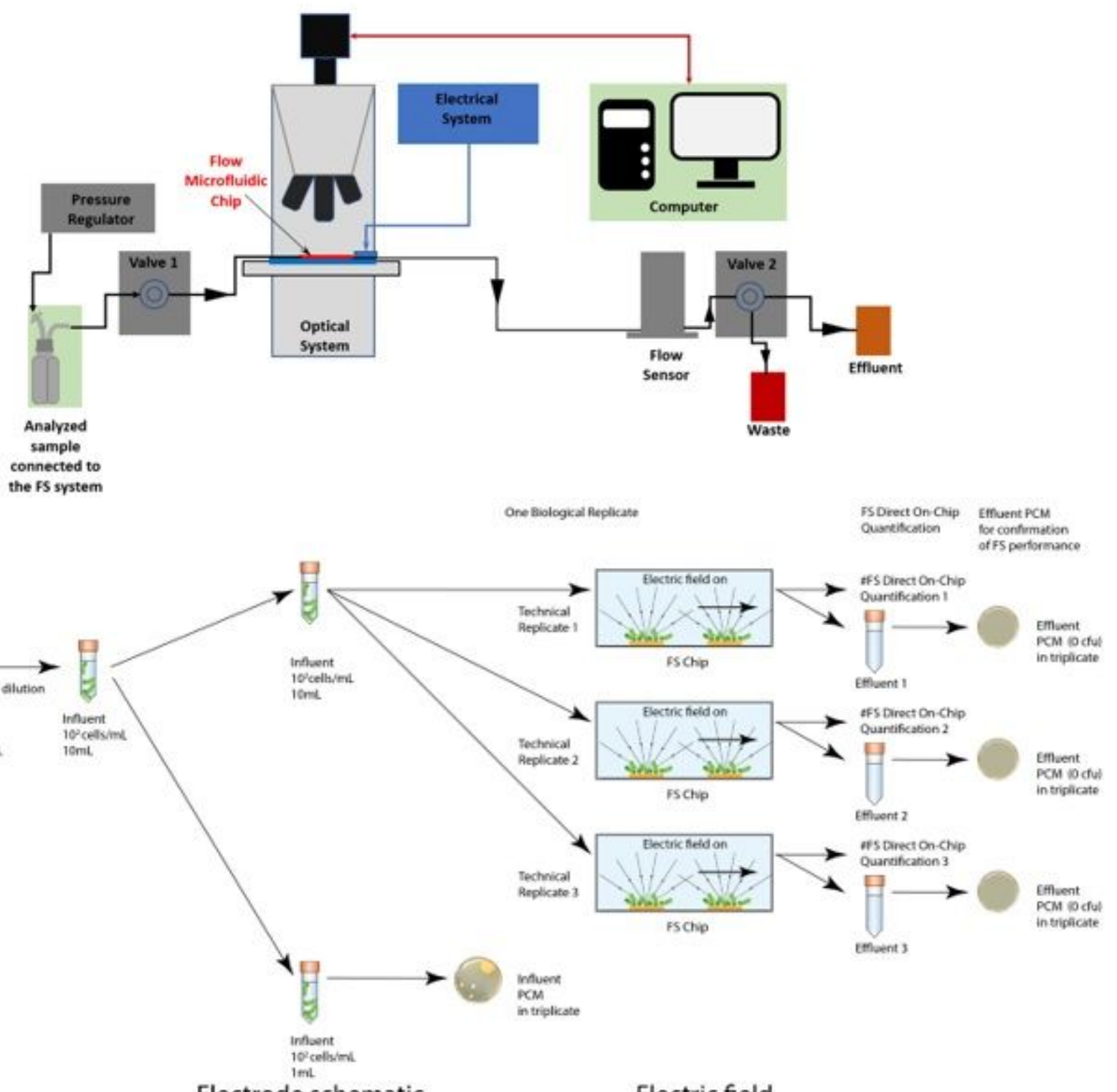

b)

Electrode schematic

c)

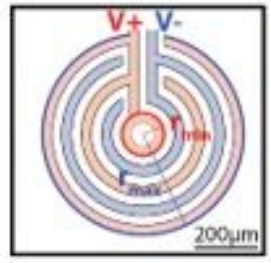

d)

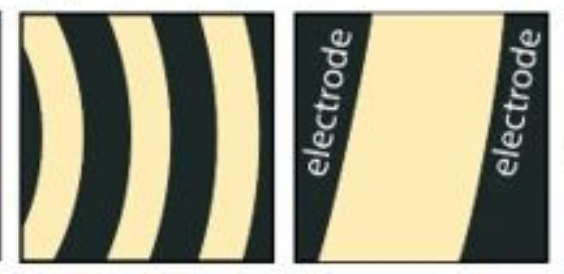

e) OFF

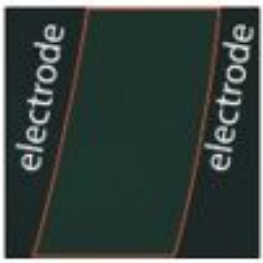

ON

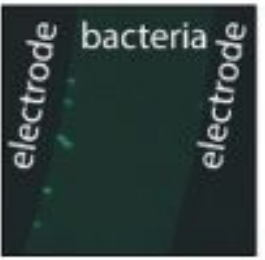

f)

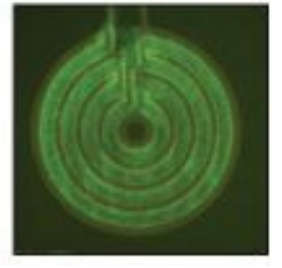

\section{Figure 1}

Graphical representation of the Fluid-Screen System (FS) with a schematic of the Fluid-Screen electrode design a) The schematic of the FS microbial capture and separation system. The influent sample enters the chip. When the electric field is turned on, bacteria are captured on the electrodes. While the electric field is turned on, the effluent sample is collected and cultured. Sample processing through FS system takes approx. 4 minutes. b) An overall schematic of the experimental procedure of bacterial capture with FS system c) An overview schematic of the electrode design (system of concentric rings), with marked 
voltage polarity. Microbial capture experiments presented in this paper were enabled by PDMS or commercial chip fabrication (see Online Methods). d) Left panel: Schematic of a part of an electrode system with applied alternating voltage polarity for the ring structure. Right panel: Zoomed-in schematic of the part of the electrode. For visual clarity the electrode is shown black, and glass, which is between electrodes, is marked yellow. e) Left panel: Fluorescent imaging shows the electrode as black, while the glass appears light green due to autofluorescence. Right panel: E. coli bacteria, expressing GFP, (green dots) captured at $10 \mathrm{MHz}$ and $10 \mathrm{Vpp}$ on the electrode edges of the ring structure. E. coli bacteria align along the electrode edges when an electric field is turned on. f) An overview of the electrode with E. coli bacteria, expressing GFP, captured from testing buffer solution spiked with bacteria. The device does not show saturation. 

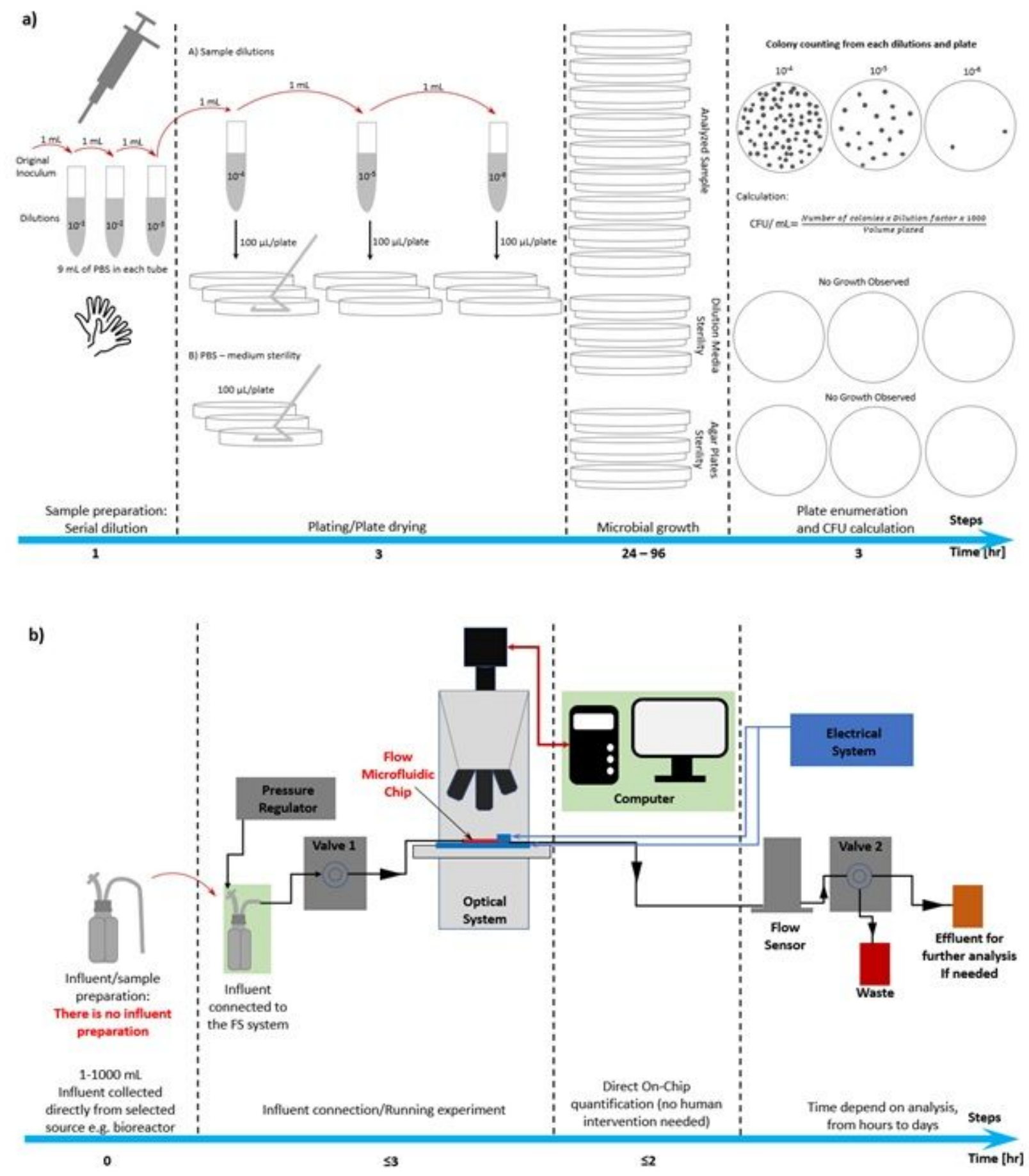

\section{Figure 2}

Comparison of the two procedures a) clinically established standard Plate Count Method (PCM) and b) FS direct "on chip quantification" approach of the Fluid-Screen microbial capture method. Schematic of an experimental setup, a part of the FS system with an indicated input (Influent), output (Effluent) sample and the Fluid-Screen Chip are shown. The FS direct "on chip quantification" is superior to the currently employed standard Plate Count Method (PCM). 


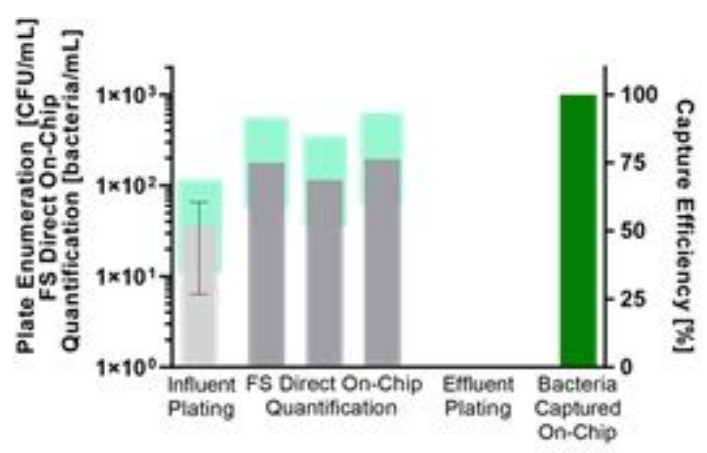

Average of three replicates biological replicate I

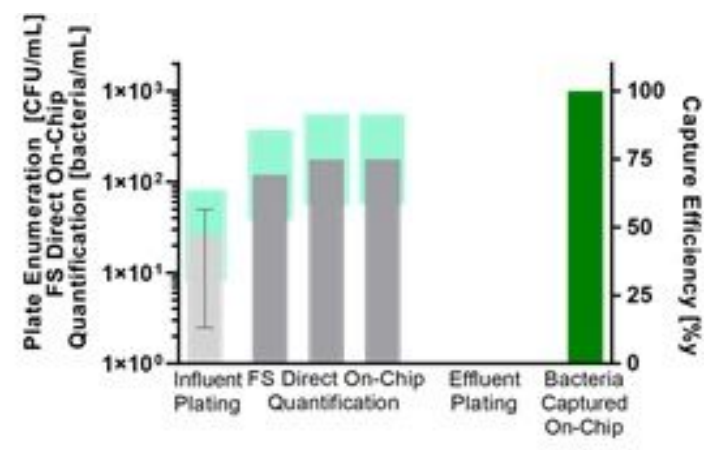

Average of three replicates biological replicate II

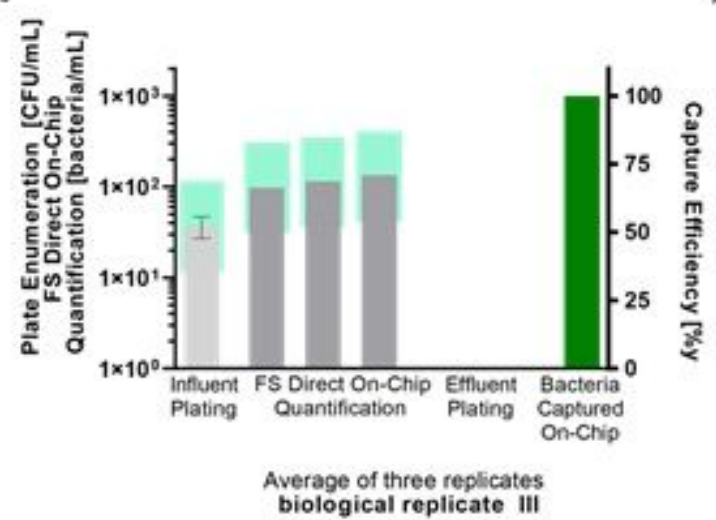

\section{Figure 3}

Verification of the efficiency of Fluid-Screen bacterial capture with the direct "on chip quantification" approach by standard plating method (PCM). Y axis: The number of cells in cfu ml-1 for plate method and cells ml- 1 as counted by FS system. Data is presented as an average from 3 technical replicates per each biological replicate. The higher error bars on the plaiting experiments are the result of variability due to manual human intervention, Fluid-Screen system is less prone to manual human error than PCM method. Note that the FS direct "on chip" microbial count is generally higher than PCM. The higher FS count is due to the fact that PCM misses cells (even if they are culturable) that are alive but, for any reason, incapable of cell division. Light green bars represent $+/-0.5$ log accepted by USP. 


\section{Side view}

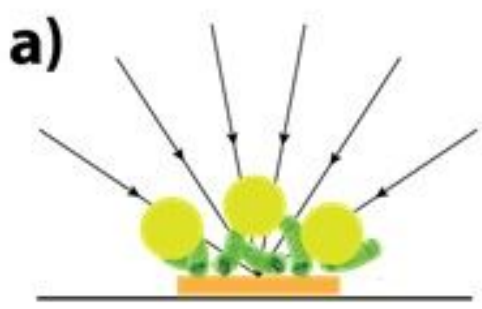

b)

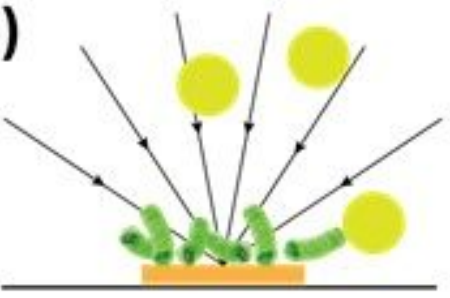

Top view
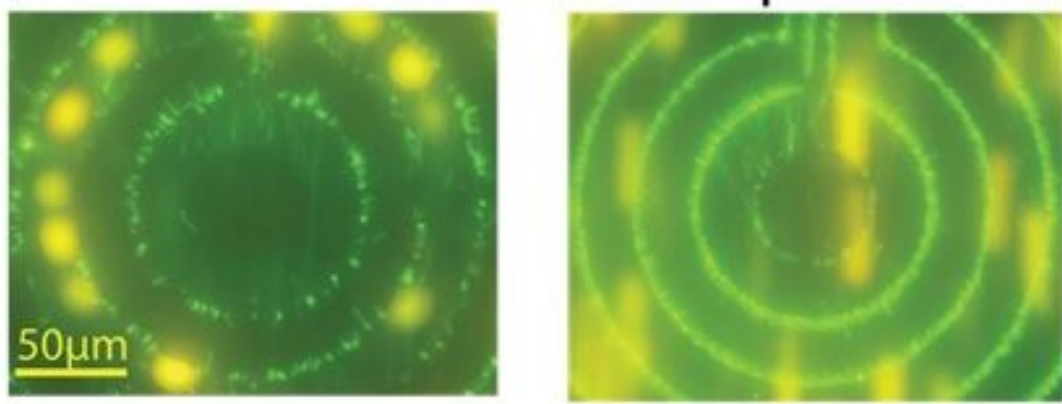

c)
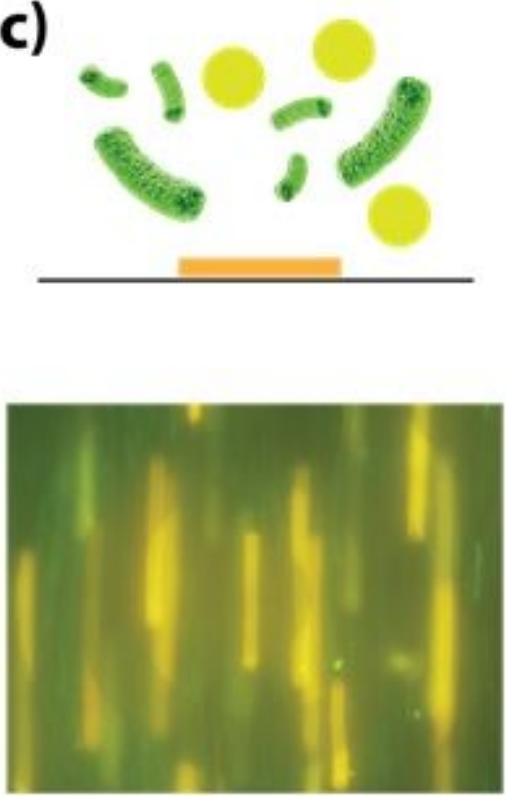

- E. coli

RBC

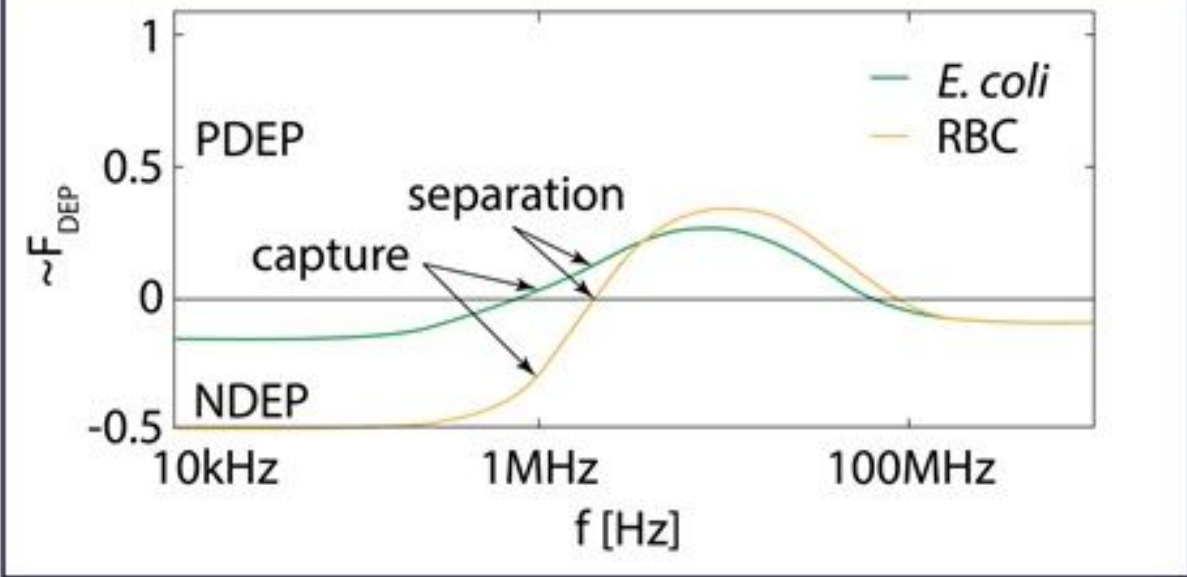

Figure 4

Capture and release of E. coli and RBCs from 10 times diluted human blood, a) simultaneous E. coli (green) and RBC (yellow) dielectrophoresis capture at $\mathrm{f} 2=2 \mathrm{MHz}$ with FS chip (orange bar) $b$ ) simultaneous E. coli (green) dielectrophoresis capture at $\mathrm{f} 1=10 \mathrm{MHz}$ and $\mathrm{RBC}$ (orange) flow separation, c) E. coli (green) and RBC (orange) flow in the absence of electric field. d) Calculated DEP force (PDEP) for E. coli and RBCs. Experimental results confirm the theoretical predictions. In solution conductivity 100 mS m-1 E. coli bacteria have a positive DEP force at $2 \mathrm{MHz}$ and at $10 \mathrm{MHz}$, calculated DEP force for RBCs, calculations show DEP force $=0$ at $2 \mathrm{MHz}$ and a positive DEP force at $10 \mathrm{MHz}$. The DEP force was calculated using model19.

\section{Supplementary Files}


This is a list of supplementary files associated with this preprint. Click to download.

- SIFluidScreenNatureMethodsPaperv4.0.pdf 